Vicios ocultos o bienes disconformes:

¿Incumplimiento y/o saneamiento?

Guillermo Arribas I.*

En el presente artículo, el Dr. Arribas presenta un análisis detallado acerca de los vicios ocultos en las obligaciones contractuales. En este sentido, presenta los efectos y remedios que pueden surgir ante un vicio no revelado.

Abogado. Profesor de Derecho de Contratos y Derechos Reales en la Pontificia Universidad Católica del Perú y de Derecho de Propiedad en la Universidad Privada de Ciencias Aplicadas. Asociado del estudio Payet, Rey, Cauvi, Perez, Mur. 


\section{Vicios ocultos o bienes disconformes: ¿Incumplimiento y/o saneamiento?}

\section{Introducción}

Rufino es propietario del conocido hotel "Sabirra", ubicado en la ciudad de Piura. El Hotel Sabirra viene operando por más de 10 años. Rufino decidió hacer una remodelación completa del hotel en el año 2012. Como parte importante de la remodelación Rufino se propuso reemplazar las clásicas cerraduras de llave metálica por modernos dispositivos de cerraduras electromagnética con tarjeta.

En enero de 2012 Rufino suscribió un contrato con Card S.A, por medio del cual Card se obligaba a suministrar, instalar y dar mantenimiento a las cerraduras electromagnéticas. Card cumplió puntualmente con los plazos de entrega, estando todo el nuevo sistema de cerraduras instalado para abril de 2012.

Luego de la remodelación, el hotel Sabirra siguió operando de manera acostumbrada. El sistema de cerraduras electromagnéticas recibía mantenimiento de manera trimestral por Card.

En el año 2013 el hotel Sabirra comenzó a recibir reclamos de sus clientes quienes alegaban que extraños habían entrado a sus habitaciones, extrayendo sus pertenencias. Sin embargo, las cerraduras y las puertas no habían sido forzadas, se encontraban intactas.

Al revisar las grabaciones de las cámaras de seguridad Rufino constató que los intrusos ingresaban tranquilamente a la habitación, sin emplear fuerza alguna. Tras revisar detalladamente la evidencia, Rufino descifró el mecanismo utilizado por los inesperados visitantes: al exponer las cerraduras electromagnéticas a imanes caseros las cerraduras fallaban y cedían.

Sorprendido, Rufino constató que otros colegas hoteleros habían sufrido el mismo desfalco. Todos los casos coincidían en que se había instalado cerraduras electromagnéticas de Card. En el sector hotelero no se reportaban fallas similares con cerraduras equivalentes de otras compañías.

Como es lógico, Rufino, y sus demás colegas hoteleros, tuvieron que reponer las pertenencias perdidas de sus pasajeros, debiendo desembolsar considerables montos de dinero. Al reclamar estos percances a Card, la compañía respondió que efectivamente conocían del problema pero que el plazo de caducidad por vicios ocultos había transcurrido, 3 meses para bienes muebles.

Rufino responde las alegaciones de Card con lógica firme de comerciante: "solicité cerraduras que funcionarán correctamente, estas no lo hacen". Rufino alega el incumplimiento de la obligación de Card, pero, ¿es eso posible?, ¿la entrega de un bien viciado puede causar un incumplimiento contractual?, y, en caso sea así, ¿se puede alegar el incumplimiento contractual cuando existe un vicio oculto? 
En derecho civil peruano se ha escrito muy poco sobre la relación entre los remedios por existencia de vicios ocultos e incumplimiento por entrega de bien disconforme 0 defectuoso. ¿Estas figuras se superponen, pueden coexistir o son incompatibles? El problema a resolver es, ¿Card debe responder por el daño sufrido por Rufino?, ¿un vendedor que entrega un bien defectuoso o viciado se libera de responsabilidad después de 3 meses para bienes muebles y 6 meses para bienes inmuebles?

El sistema de saneamiento por vicios ocultos, como veremos, trata de proteger al comprador. En el saneamiento por vicios el comprador no debe probar la culpa del vendedor, vasta la existencia del vicio, que sea oculto y que exista antes o al momento de la transferencia del bien. En cambio, los remedios contractuales por incumplimiento de obligaciones requieren que el comprador pruebe los elementos de la responsabilidad por inejecución de obligaciones, entre ellos la culpa.

No obstante, la protección especial por vicios ocultos tiene una fecha de corte, un plazo de caducidad indiscutible: 3 meses para bienes muebles y 6 meses para bienes inmuebles. Los remedios por incumplimiento de obligaciones, en cambio, pueden ser reclamados hasta por 10 años luego del incumplimiento.

De considerar que el sistema de vicios ocultos excluye los remedios por incumplimiento nos encontramos frente a una alarmante conclusión: un remedio supuestamente más eficiente por 3 meses excluiría la protección integral del comprador por 10 años.

\section{Vicios Ocultos}

\subsection{Vicios del bien entregado y falta de cualidades prometidas}

El régimen de saneamiento por vicios ocultos está regulado en los artículos 1503 y siguientes del Código Civil. Básicamente se incluyen dos supuestos dentro de los posibles vicios: (i) vicios en el bien entregado o (ii) falta de cualidades prometidas. Los artículos 1503 y 1505 indican:

"Artículo 1503.- El transferente está obligado al saneamiento por los vicios ocultos existentes al momento de la transferencia."

"Artículo 1505.- Hay lugar al saneamiento cuando el bien carece de las cualidades prometidas por el transferente que le daban valor o lo hacían apto para la finalidad de la adquisición".

Se debe tener presente que la distinción entre "vicio" y "falta de cualidades prometidas" no proviene del Código Civil, sino más bien de la doctrina. Algunos autores sostienen, incluso, que en realidad el vicio y la falta de cualidad prometida son lo mismo: un bien que no cumple con el interés del acreedor.

Aguayo en España explica sobre la diferencia clásica entre vicio y falta de cualidades prometidas: 
"Si la utilidad qué se pretende extraer de la cosa es la habitual en objetos de su mismo género, la presencia del vicio comportará la ausencia de una cualidad que normalmente no habrá sido objeto de una previsión contractual expresa, ya que las partes no suelen pactar que la cosa vendida carezca de defectos que la hagan impropia para su destino habitual. Pero si, en cambio, la utilidad que se pretende extraer de la cosa comprada no es la habitual, la presencia del vicio supondrá normalmente la ausencia de una cualidad especialmente prevista en el contrato y, si no lo está, será el comprador quien deba probar que adquirió la cosa para destinarla a un uso que es el habitual y que el vendedor conoció o debió haber conocido dicha circunstancia". ${ }^{1}$

Manuel de la Puente ${ }^{2}$, en derecho peruano, y Doménico Rubino ${ }^{3}$, en derecho italiano, coinciden con la diferenciación señalada por Aguayo. Vicio es la falta de una cualidad esencial del bien que ha sido entregado, en cambio la falta de cualidad prometida, o defecto de calidad, es la inexistencia de una característica especial del bien, distinta a las típicas.

De la Puente grafica la distinción entre vicio y cualidades prometidas con el siguiente ejemplo:

"Por ejemplo, en el caso de automóviles de una cierta marca que desarrollan una velocidad máxima promedio de 150 kilómetros por hora, se afirma que un determinado automóvil de esa marca desarrolla hasta 200 kilómetros por hora. Es esta especial velocidad máxima la que hace apto el automóvil para la finalidad buscada por el adquirente. ${ }^{\prime 4}$.

Si se compra el automóvil del ejemplo, y este no alcanza la velocidad de $150 \mathrm{~km}$ por hora, estaríamos ante un vicio. En cambio, si se pacta que el auto debe alcanzar una velocidad de $200 \mathrm{~km}$ por hora, o se intuye del contexto que debe llegar a esta velocidad (e.g. el comprador es un corredor de autos que siempre ha comprado el mismo tipo de auto al vendedor), estaríamos ante la falta de una cualidad prometida.

Por esta razón, en el caso de vicios es indiferente si en el contrato, por ejemplo de compraventa, se detalla expresamente qué cualidades tendrá el bien vendido, porque son características necesarias y típicas del bien. En cambio, en el caso de cualidades prometidas, sí será recomendable incluir expresamente estas cualidades especiales. Si las cualidades especiales no son expresamente previstas en el contrato, el comprador

1 Aguayo, Juan, "Las Manifestaciones y garantías en el derecho de contratos español", Civitas, Madrid, p.349.

2 De la Puente, Manuel, "El Contrato en General". T. III, Fondo Editorial de la PUCP, p. 449.

3 Rubino, Doménico, "La responsabilidad por defecto de calidad en la compraventa y sus diferencias con la garantía por vicios según el código civil italiano", En: Revista de Derecho Privado, pp. 165 y siguientes.

4 De la Puente, Manuel, "El Contrato en General". T. III, Fondo Editorial de la PUCP, p. 451. 
tendrá que probar que el vendedor sabía, o debió saber, que el bien vendido tenía que incluir estas cualidades adicionales.

En el ejemplo de Rufino y Card estaríamos ante un típico caso de vicio, porque dentro de las características básicas de una cerradura consideramos que se encuentra que esta no falle por un defecto de sistema. Estaríamos, en el mismo ejemplo, ante falta de cualidades prometidas en el supuesto que Rufino haya solicitado de manera especial que todas las tarjetas de las cerraduras tengan impreso el nombre del hotel "Sabirra" y Card imprime en ellas "Zabirra". A pesar de no ser una característica intrínseca al sistema vendido por Card, debido al pacto contractual existiría una falta de cualidad prometida.

\subsection{Remedios legales para vicios ocultos}

El Código Civil peruano, al igual que el sistema legal español y muchos otros, prevé dos tipos de remedios para los vicios ocultos: la acción redhibitoria y la acción estimatoria. Ambos remedios son aplicables frente a un vicio o la falta de una cualidad prometida. A pesar que como explicamos en la sección anterior nuestro Código Civil ha distinguido, por lo menos en cuanto a nombre, entre los vicios y la falta de cualidades prometidas, se aplica el régimen de vicios ocultos a ambos casos.

La acción redhibitoria y la acción estimaría están reguladas en los artículos 1511 y 1513 del Código Civil:

"Artículo 1511.- El adquirente puede pedir, en razón del saneamiento a que está obligado el transferente, la resolución del contrato."

"Artículo 1513.- El adquirente puede optar por pedir que se le pague lo que el bien vale de menos, por razón de vicio, en el momento de ejercerse la acción de pago, teniendo en cuenta la finalidad de su adquisición, sin perjuicio del derecho que contempla el artículo 1512, inciso 5."

Por la acción redhibitoria el adquirente solicita la resolución del contrato, en cambio, en la acción estimatoria, el adquirente solicita la reducción del precio. Debido a esta distinción se suele sostener que el vicio debe ser grave solo para el caso de la acción redhibitoria, siguiendo la misma lógica que la resolución por incumplimiento contractual. Aguayo explica al respecto:

"Se ha sostenido que el vicio ha de ser grave pero, como hemos señalado supra, creemos que la gravedad es exigible únicamente para la acción redhibitoria"

El Código Civil peruano reconoce esta lógica en el artículo 1515, la norma dice:

5 Aguayo, Juan, "Las Manifestaciones y garantías en el derecho de contratos español", Civitas, Madrid, p. 364. 
"Cuando se trata de vicios de poca importancia, el transferente puede ofrecer subsanarlos, si esto es posible. Si la oferta es rechazada por el adquirente, éste puede intentar sólo la acción estimatoria, perdiendo la redhibitoria."

Es decir, cuando se trata de vicios de poca importancia, en última instancia el adquirente solo podrá exigir la reducción del precio, más no la resolución del contrato. La acción redhibitoria extingue la relación contractual porque se entiende que si el adquirente hubiese sabido del vicio no habría celebrado el contrato, por esto el vicio debe ser importante. En cambio, la acción estimatoria tiene como objetivo restablecer el equilibrio contractual, para ello no es relevante la importancia del vicio, sino que el bien valga efectivamente lo que se está pagando por él.

Imaginemos por ejemplo que una persona compra un automóvil y solicita que el vendedor coloque pintura cromada en algunas secciones del automóvil. El automóvil sin la pintura cromada tiene un precio de $\$ 27,000$ y con la pintura $\$ 28,000$.

En caso el vendedor no coloque la pintura en las secciones correspondientes del automóvil no estaremos, en general, ante un defecto esencial, a pesar de sí ser un defecto. La falta de pintura cromada hace que el bien valga $\$ 1000$ menos. A pesar de no poder resolver el contrato, a través de la acción estimatoria el comprador pagará \$ 27,000 , logrando equilibrio entre las prestaciones de las partes.

En adición a la importancia del vicio, nuestro Código Civil establece los siguientes dos requisitos para que se apliquen las normas de saneamiento por vicios ocultos:

(i) Oculto: el adquirente no debe haber conocido de la falla del bien transferido al momento de su entrega.

(ii) Anterior o contemporáneo a la transferencia: el vicio tiene que preexistir a la entrega del bien.

\section{III. ¿Vicio oculto y/o disconformidad de bienes?}

¿La entrega de un bien viciado puede ser también un incumplimiento por la entrega de un bien disconforme? La falla de diseño de las cerraduras electromagnéticas vendidas a Rufino, ¿es un vicio, un incumplimiento o ambos?

El Código Civil peruano no distingue claramente entre el régimen de incumplimiento de contrato por entregar un bien disconforme, asimilable al cumplimiento defectuoso, y el régimen de vicios ocultos. De hecho, la exposición de motivos del Código Civil tampoco abarcó o desarrolló este punto ${ }^{6}$.

$6 \quad$ Ver: Osterling, Felipe, Reboredo, Delia (compiladora), "Exposición de Motivos del Código Civil', pp. 438 y siguientes; ARIAS SHREIBER, Max y otros, Reboredo, Delia (compiladora). "Exposición de Motivos del Código Civil", pp. 181 - 184. 
En derecho comparado se ha determinado que estas dos figuras, la entrega de un bien viciado y el incumplimiento por entrega de un bien conforme, están superpuestas, optándose en algunos casos como en la Convención de las Naciones Unidas sobre los Contratos de Compraventa Internacional de Mercaderías ("Convención de Viena") por eliminar el régimen de vicios ocultos y mantener solamente el incumplimiento por falta de conformidad del bien entregado. En esta misma línea Aguayo comenta al referirse a una propuesta legislativa que incluiría el incumplimiento por falta de conformidad de manera general en el Código Civil español, tal como lo hace el derecho de consumo español y la Convención de Viena:

"Si entrara en vigor, el incumplimiento por falta de conformidad se extendería a las compraventas realizadas fuera del derecho de consumo, sustituyendo completamente el régimen de saneamiento por vicios ocultos." ${ }^{\prime \prime}$.

A pesar que los remedios por vicios ocultos e incumplimiento contractual son distintos, su causa coincide: se entrega un bien distinto al prometido o esperado. Si Rufino contrató con Card para que le entregaran cerraduras electromagnéticas sin fallas, y las entregadas tenían fallas, existe un cumplimiento defectuoso de la obligación. Si bien Card entregó las cerraduras, estas no eran las cerraduras prometidas a Rufino.

En doctrina y jurisprudencia española se ha desarrollado el concepto de aliud pro alio para referirse a aquellos casos donde se incumple el contrato al entregar un bien distinto al ofrecido o esperado. Gili explica al respecto:

"La doctrina jurisprudencial del aliud pro alio encuentra su fundamento en el art. 1166 CC: "[e]l deudor de una cosa no puede obligar a su acreedor a que reciba otra diferente, aun cuando fuere de igual o mayor valor que la debida". Se entrega, pues, una cosa diversa cuando hay pleno incumplimiento por inhabilidad del objeto y consiguiente insatisfacción del comprador, esto es, cuando la falta -ontológica o funcional- en las cualidades del bien entregado es tan grave que se puede equiparar a un incumplimiento contractual. Asimismo, el Tribunal Supremo incluye aquellos casos en los que, produciéndose una identidad objetiva y natural, la prestación ofrecida es inhábil en relación con el objeto o inidónea para cumplir las finalidades o intereses del acreedor cuando éstos han sido conocidos por el deudor. ${ }^{\prime \prime}$

Aguayo, Juan, "Las Manifestaciones y garantías en el derecho de contratos español", Civitas, Madrid, p. 407.

8 Gili, Marian, "Compraventa de acciones: causa del contrato y remedios frente al cincumplimiento de las manifestaciones y garantías", En: InDret, Revista para el análisis del Derecho, Barcelona, 2010, p. 9. 
El incumplimiento contractual en estos casos responde a la disconformidad del bien entregado. El artículo 35 inciso 2 de la Convención de Viena regula en detalle este tipo incumplimiento contractual:

"2. Salvo que las partes hayan pactado otra cosa, las mercaderías no serán conformes al contrato a menos que:

a) que sean aptas para los usos a que ordinariamente se destinen mercaderías del mismo tipo;

b) que sean aptas para cualquier uso especial que expresa o tácitamente se haya hecho saber al vendedor en el momento de la celebración del contrato, salvo que de las circunstancias resulte que el comprador no confió, o no era razonable que confiara, en la competencia y el juicio del vendedor;

c) que posean las cualidades de la muestra o modelo que el vendedor haya presentado al comprador;

d) que estén envasadas o embaladas en la forma habitual para tales mercaderías o, si no existe tal forma, de una forma adecuada para conservarlas y protegerlas.

$[\ldots]^{\prime \prime}$

A pesar de lo mencionado, Manuel de la Puente adopta una lectura restrictiva del aliud pro alio, considerándolo solo aplicable cuando el bien es totalmente distinto, perteneciendo a otro género:

"Se entiende por "aliud pro alio" cuando el bien es completamente distinto del que ha sido materia del contrato, o sea pertenece a otro género" ${ }^{\prime \prime}$.

Es decir, para De la Puente si Card hubiese entregado a Rufino cerraduras clásicas de llave en lugar de electromagnéticas de tarjeta, se aplicaría el aliud pro alio. En cambio, si Card entregaba cerraduras electromagnéticas falladas o inutilizables, estaríamos ante un vicio.

No se debe perder de vista lo mencionado previamente, tanto en el caso de vicios, falta de cualidades prometidas y entrega de bien disconforme el supuesto fáctico es el mismo: se entrega un bien distinto al prometido o esperado. Por esto, no podemos compartir la posición de De la Puente, en los 3 casos mencionados se entrega bienes disconformes, en los 3 casos el bien no satisface el interés del acreedor. La real importancia de esta diferenciación, o no diferenciación mejor dicho, recae en los remedios aplicables, en un caso vicios ocultos y en el otro incumplimiento contractual, tema de la siguiente sección.

\section{Remedio, ¿Y u O?}

9 De la Puente, Manuel, "El Contrato en General", T. III, Fondo Editorial de la PUCP, p. 452. 
Es fundamental responder la pregunta enunciada, si se entregan bienes disconformes, ¿es posible aplicar los remedios previstos para el incumplimiento contractual y/o vicios ocultos?, ¿Rufino puede demandar el incumplimiento contractual de Card a pesar de haber pasado 3 meses de la entrega de las cerraduras?

Tanto en el incumplimiento contractual como en vicios ocultos estamos dentro de la responsabilidad por inejecución de obligaciones, el incumplimiento contractual siendo la regla general y la responsabilidad por vicios ocultos el régimen especial. La importancia para este caso está en las características que estos remedios presentan. Como principales diferencias se podría resumir:

\begin{tabular}{|l|l|l|}
\cline { 2 - 4 } \multicolumn{1}{c|}{} & \multicolumn{1}{c|}{ VICIOS OCULTOS } & \multicolumn{1}{c|}{$\begin{array}{c}\text { INCUMPLIMIENTO } \\
\text { CONTRACTUAL }\end{array}$} \\
\hline Remedios & $\begin{array}{l}\text { Resolución del contrato (acción } \\
\text { redhibitoria) o reducción de } \\
\text { precio (acción estimatoria) }\end{array}$ & $\begin{array}{l}\text { Resolución del contrato y/o } \\
\text { indemnización por incumplimiento } \\
\text { contractual }\end{array}$ \\
\hline Culpa & $\begin{array}{l}\text { No es necesario probar la culpa, } \\
\text { la sola existencia del vicio hace } \\
\text { imputable al transferente } \\
\text { (responsabilidad objetiva) }\end{array}$ & $\begin{array}{l}\text { Es necesario probar la culpa, la } \\
\text { existencia del vicio debe estar } \\
\text { acompañada de la culpa del } \\
\text { transferente } \\
\text { objetiva) }\end{array}$ \\
\hline Plazos & $\begin{array}{l}\text { Plazo de caducidad de 3 meses } \\
\text { para bienes muebles y } 6 \text { meses } \\
\text { para bienes inmuebles }\end{array}$ & $\begin{array}{l}\text { Plazo de prescripción general de 10 } \\
\text { años }\end{array}$ \\
\hline
\end{tabular}

Si los remedios por vicios ocultos e incumplimiento contractual no se pudieran aplicar copulativamente, Rufino tendría el siguiente problema: su acción contra Card efectivamente habría caducado. Si bien en el régimen de vicios ocultos no es necesario probar la culpa, por lo que en principio se mejora la situación del adquirente en un eventual conflicto, este remedio especial tiene una vigencia sustancialmente más corta en comparación con el régimen de incumplimiento contractual.

A nivel de derecho comparado existen posiciones distintas respecto a la posibilidad de utilizar de manera conjunta los remedios por vicios ocultos e incumplimiento

$10 \quad$ "Artículo 1514.- Las acciones a que se refieren los artículos 1511 y 1513 caducan a los tres meses si se trata de bienes muebles y a los seis, de inmuebles. Los plazos se computan desde el momento de la recepción del bien."

11 "Artículo 2001.- Prescriben, salvo disposición diversa de la ley:

1.- A los diez años, la acción personal, la acción real, la que nace de una ejecutoria y la de nulidad del acto jurídico. (...)". 
contractual. Estas posiciones, como es obvio, se generan en sistemas donde el régimen general incumplimiento contractual coexiste con el régimen especial de vicios ocultos. En España Badanes señala:

"Como se ha expuesto, el Código Civil, siempre por influencia de la tradición, se ha alejado del sistema de las obligaciones y de los contratos, dejando abiertos al comprador dos caminos de modo alternativo, y excluyendo un tercero que debería ser el primero, no sólo porque es el más natural, sino también porque es el que mejor responde a los gastos generales.

La vía más natural, a que se alude, hubiera sido la del cumplimiento, que es el primer deber, el deber originario, fundamental del obligado por contrato o por cualquier otra fuente ${ }^{\prime 12}$.

Badanes considera que no es posible emplear los remedios generales del incumplimiento contractual, ello porque el régimen especial primaría sobre el régimen general. No obstante, Badanes sí considera que es un error del sistema excluir los remedios por incumplimiento en estos casos. De la cita de Badanes se desprende una conclusión adicional, Badanes también considera que más allá de las diferentes etiquetas (vicio, falta de cualidades prometidas o disconformidad del bien), se está frente al mismo supuesto: la entrega de un bien que no satisface el interés del acreedor. Es por esto que concluye que no se puede aplicar el incumplimiento contractual, de otro modo no sería necesario si quiera mencionarlo porque serían supuestos de hecho distintos.

En cambio, en Alemania Ennecerus afirma:

"En virtud de un vicio del objeto comprado, puede exigirse indemnización no sólo cuando concurre uno de los casos determinados en los artículo 463 y 480 [referido a los vicios ocultos], sino también, en virtud de una regla general, cuando el vicio haya sido provocado culpablemente por el vendedor $(\ldots)^{\prime \prime 13}$.

Para Ennecerus será posible alegar, en adición a los remedios por vicios ocultos, una indemnización cuando el transferente haya actuado con culpa. Como explicamos, una de las grandes diferencias en cuanto a los remedios por vicios ocultos e incumplimiento contractual está en la necesidad de probar o no la culpa. Lo que afirma Ennecerus, en otras palabras, es que en caso el transferente actúe con culpa se podrá reclamar la responsabilidad tanto por vicios ocultos como por incumplimiento de obligaciones.

La doctrina alemana sustenta la postura de Ennecerus en que no debe desprotegerse al acreedor en caso exista una violación positiva del contrato. Si, por ejemplo, existiera un vicio pero no existiera culpa, no habría necesidad de aplicar esta teoría porque bajo

12 Badanes, Ramón, "Contrato de Compraventa", Bosch, Barcelona, p. 664.

13 Ennecerus, Ludwig; Kipp, Theodor y Martin, Wolff. "Tratado de Derecho Civil'. T. II, Vol. 1, Bosch, Barcelona, p. 286. 
el régimen general de incumplimiento de obligaciones tampoco existiría responsabilidad.

Aplicar de manera copulativa las normas de incumplimiento contractual y vicios ocultos, finalmente, busca:

(i) Dentro de la relación contractual, superar el plazo de caducidad de vicios ocultos y otorgar al acreedor un régimen más flexible para satisfacer su interés.

(ii) Fuera de la relación contractual, desincentivar actividades dañosas. La culpa en el régimen de responsabilidad civil general establece un estándar de conducta adecuada, si se actúa fuera de ese estándar y se causa un daño este deberá ser indemnizado. Cuando existe culpa y se obliga a pagar una indemnización, el mensaje que se envía al sistema es: no incumplas tu contrato porque tendrás que pagar por ello. Se trata de desincentivar una actividad dañosa, si el transferente entrega un bien disconforme con culpa y no se le puede hacer responsable por un plazo de 3 meses vencido, existiría una contradicción y un vacío inaceptable en el régimen de responsabilidad civil por inejecución de obligaciones.

En derecho peruano también encontramos esta discusión. De la Puente afirma:

"En efecto, concordando los artículos 1503 y 1505 del Código Civil peruano puede llegarse a la conclusión que los vicios ocultos y la carencia de cualidades prometidas dan lugar al saneamiento, que se puede alcanzar a través de las acciones redhibitoria y estimatoria. En cuanto al aliud pro alio, por tratarse de un caso evidente de incumplimiento contractual, las acciones pertinentes son la de solicitar el cumplimiento y, en el caso específico de los contrato con prestaciones recíprocas, la de resolución de la relación jurídica creada"14${ }^{14}$.

Como explicamos, de la Puente sostiene una postura restringida del aliud pro alio y, consecuente con ello, afirma que en derecho peruano cuando existe vicio o falta de cualidades prometidas no se podrán aplicar los remedios por incumplimiento contractual. Sin perjuicio de la coherencia lógica, la postura de Manuel de la Puente contiene un vicio difícil de subsanar.

Para de la Puente solo estaremos ante incumplimiento por disconformidad de bienes si el bien entregado pertenece a un género distinto. Por ejemplo, A pacta un contrato de compraventa con $\mathrm{B}$ por el cual $\mathrm{B}$ transferirá a $\mathrm{A}$ un caballo de carrera a cambio de lo cual A pagará un precio. Según de la Puente, si llegada la fecha de entrega del caballo, $B$ entrega a A un burro de carga, A podrá alegar incumplimiento contractual y no vicio oculto.

14 De la Puente, Manuel, "El Contrato en General". T. III, Fondo Editorial de la PUCP, pp. 454 y 455. 
Siguiendo nuevamente a de la Puente, si B se obliga a entregar a A el caballo de carrera "Rayo" que había ganado 10 carreras y resulta que entrega el caballo "Rayo" que solo había ganado 5, A no puede alegar incumplimiento contractual porque finalmente se ofreció un caballo y se entregó un caballo, mismo género. ¿Qué ocurre si después de 3 meses A descubre que "Rayo" solo había ganado 5 carreras? Para de la Puente absolutamente nada, ya habría caducado el plazo para reclamar vicios ocultos y no estamos ante un incumplimiento contractual. No interesaría que en el contrato se haya previsto expresamente que "Rayo" había ganado 5 carreras, una cualidad prometida del caballo. No es correcto.

En contraste a lo mencionado por de la Puente, Jose Antonio Payet sostiene:

"Debe preguntarse si la existencia de normas específicas respecto a la responsabilidad del vendedor por la entrega de una cosa defectuosa [vicios ocultos] debe excluir, para los supuestos correspondientes, la aplicación de los principios de mayor generalidad sobre la violación positiva del crédito. De acuerdo a la doctrina dominante, tales circunstancias no pueden implicar la exclusión de las disposiciones generales sobre violación positiva del crédito por las normas especiales sobre la garantía en el contrato de compraventa"15.

Payet coincide con la posición de Ennecerus. Considera que de existir un bien disconforme, defectuoso o con vicio, como sea que le llamemos, se deben aplicar de manera copulativa tanto las normas específicas de vicios ocultos como las generales de incumplimiento. Esta postura definitivamente protege de manera adecuada el interés del acreedor.

En lo particular, consideramos que si solo existiera la norma general de incumplimiento de obligaciones y la norma especial de vicios ocultos, igual se podrían aplicar copulativamente los remedios por vicios ocultos e incumplimiento de obligaciones. Por supuesto, en caso se obtenga una indemnización por incumplimiento de obligaciones no correspondería reducir el precio de venta a través de la acción estimatoria por vicios ocultos, ello sería un enriquecimiento sin causa, pero se debería poder utilizar la acción que mejor satisfaga el interés del acreedor.

El sustento para emplear ambos remedios ya ha sido explicado: (i) a nivel interno, proteger de manera adecuada el interés del acreedor, (ii) a nivel externo, no dejar impune actividades dañosas culposas de los agentes del mercado. En el caso de Rufino, si no se aplicaran copulativamente ambos remedios, Card, a pesar de haber conocido de los defectos, no tendría que responder por sus actos.

Sin perjuicio de lo mencionado, consideramos que en derecho peruano existe norma expresa que habilita la aplicación copulativa de los remedios por incumplimiento

15 Payet, José Antonio, "La responsabilidad por productos defectuosos". T. I, Fondo editorial de la PUCP, Lima, 1990, p. 325. 
contractual y vicios ocultos. Ello principalmente en base a lo previsto en el artículo 1512 inciso 5, norma que forma parte de la sección de vicios ocultos:

"Artículo 1512.- La resolución a que se refiere el artículo 1511 impone al transferente la obligación de pagar al adquirente:

[...]

5.- La indemnización de daños y perjuicios, cuando el transferente haya incurrido en dolo o culpa respecto de la existencia de los vicios."

De acuerdo a la norma, cuando se entrega un bien disconforme se activan a favor del adquirente: (i) los remedios generales por vicios ocultos y (ii) si hubo culpa, responsabilidad por incumplimiento de las obligaciones contractuales del transferente. Por esta razón Jorge Beltrán al comentar el inciso 5 del artículo 1512 afirma:

"El sistema de responsabilidad civil aplicable en el presente caso sería el sistema de responsabilidad poscontractual, pero al no estar regulado se deben aplicar las normas de la responsabilidad por inejecución de obligaciones." ${ }^{\prime 16}$.

Los remedios típicos de saneamiento por vicios ocultos no incluyen la indemnización por incumplimiento de obligaciones, sin embargo, el inciso 5 del artículo 1512 habilita expresamente al adquirente a demandar estos daños en caso el transferente haya actuado culposamente. Esto no solo implica que se podría demandar el incumplimiento contractual en adición a la acción de saneamiento, sino que además el plazo de caducidad de 3 meses de la acción por vicios ocultos estaría acompañado del plazo de prescripción de 10 años para incumplimiento de obligaciones.

\section{Conclusión}

La ley peruana, a pesar de ser más asertiva que la ley española o italiana, no marca una clara relación entre los remedios por incumplimiento contractual y vicios ocultos. Esta deficiencia de la ley no es excusa para desproteger a los adquirentes, es necesario interpretar la norma.

¿Rufino tendría una acción contra Card? Consideramos que sí, un rotundo sí. Más allá de las etiquetas colocadas por el sistema civil, ya se denomine vicio, falta de cualidad prometida o incumplimiento por entrega de bien disconforme, las tres figuras tienen la misma causa: el acreedor recibe un bien que no satisface su interés. Rufino, como cualquier adquirente, podrá alegar la existencia de vicios ocultos y, de manera copulativa, incumplimiento contractual, siempre que existan los requisitos necesarios de acuerdo a lo previsto en la ley.

16 Beltrán, Jorge, "Código Civil comentado por los 100 mejores especialistas". Gaceta Jurídica, Lima, p. 931. 